\title{
MicroRNA-34a Is Induced via p53 during Cisplatin Nephrotoxicity and Contributes to Cell Survival
}

\author{
Kirti Bhatt, ${ }^{1}$ Li Zhou, ${ }^{2}$ Qing-Sheng Mi, ${ }^{2}$ Shuang Huang, ${ }^{3}$ In-Xiong She, and Zheng Dong ${ }^{1}$
}

Departments of ${ }^{1}$ Cellular Biology and Anatomy and ${ }^{3}$ Biochemistry and the ${ }^{4}$ Center for Biotechnology and Genomic Medicine, Medical College of Georgia and Charlie Norwood VA Medical Center, Augusta, Georgia, United States of America; ${ }^{2}$ Departments of Dermatology and Internal Medicine, Henry Ford Health System, Detroit, Michigan, United States of America

\begin{abstract}
MicroRNAs are small noncoding RNAs that are produced endogenously and have emerged as important regulators in pathophysiological conditions such as development and tumorigenesis. Very little is known about the regulation of microRNAs in renal diseases, including acute kidney injury (AKI). In this study, we examined the regulation of microRNA-34a (miR-34a) in experimental models of cisplatin-induced AKI and nephrotoxicity. By Northern blot and real-time polymerase chain reaction analyses, we detected an induction of miR-34a in vitro during cisplatin treatment of mouse proximal tubular cells and also in vivo during cisplatin nephrotoxicity in C57BL/6 mice. In cultured cells, miR-34a was induced within a few hours. In mice, miR-34a induction was detectable in renal tissues after $1 \mathrm{~d}$ of cisplatin treatment and increased to approximately four-fold of control at $d$ 3. During cisplatin treatment, p53 was activated. Inhibition of p53 with pifithrin- $\alpha$ abrogated the induction of miR-34a during cisplatin treatment of proximal tubular cells. In vivo, miR-34a induction by cisplatin was abrogated in p53-deficient mice, a result that further confirms a role for p53 in miR-34a induction during cisplatin nephrotoxicity. Functionally, antagonism of miR-34a with specific antisense oligonucleotides increased cell death during cisplatin treatment. Collectively, the results suggest that miR-34a is induced via p53 during cisplatin nephrotoxicity and may play a cytoprotective role for cell survival.
\end{abstract}

(C) 2010 The Feinstein Institute for Medical Research, www.feinsteininstitute.org

Online address: http://www.molmed.org

doi: $10.2119 /$ molmed.2010.00002

\section{INTRODUCTION}

Cisplatin, one of the most potent chemotherapy drugs, is also a welldocumented nephrotoxin that induces acute kidney injury (AKI) in cancer patients. In kidneys, cisplatin accumulates in renal tubular cells, resulting in cell injury and death, contributing to the development of AKI (see [1,2] for reviews). Research during the last few years has identified several important signaling pathways that lead to tubular-cell apoptosis during cisplatin nephrotoxicity, including mitogen-activated protein kinase, p53 and others (3-14).

p53 is activated early after cisplatin treatment of renal tubular cells in vitro and in animals in vivo $(10,15-22)$. Pharmacological and genetic inhibition of p53 attenuates cisplatin-induced apoptosis in cultured tubular cells. An important finding was that cisplatin-induced nephrotoxicity is partially but significantly ameliorated in p53-deficient mice (22). Our recent work has further demonstrated a DNA damage response mediated by ATR-Chk2 in p53 activation and tubular cell apoptosis during cisplatin nephrotoxicity (19). After being activated, p53 can induce the expression of proapoptotic genes, such as PUMA- $\alpha$ and PIDD, to induce cell injury and death $(18,20)$. On the other hand, p53 may also activate mechanisms for cell survival. For example, p21, a cellcycle regulator with antiapoptotic activity, is induced during cisplatin nephrotoxicity via both p53-dependent and
Address correspondence and reprint requests to Zheng Dong, Department of Cellular Biology and Anatomy, Medical College of Georgia, 1459 Laney Walker Blvd., Augusta, GA 30912. Phone: (706) 721-2825; Fax: (706) 721-6120; E-mail: zdong@mail.mcg.edu.

Submitted January 4, 2010; Accepted for publication April 8, 2010; Epub

(www.molmed.org) ahead of print April 9, 2010. -independent mechanisms (23). In addition, p53 may contribute to the activation of autophagy, a cytoprotective mechanism for cell survival (24). As a result, the balance between the prodeath and prosurvival factors may determine if a cell can survive or be lethally injured during cisplatin nephrotoxicity.

MicroRNAs are small noncoding RNA molecules of 19-25 nucleotides, which regulate posttranscriptional gene regulation (25-28). MicroRNAs bind to the 3 '-untranslated regions of targetgene mRNAs, resulting in stalling of protein synthesis or mRNA degradation. MicroRNAs have emerged as critical regulators of a variety of physiological as well as pathological conditions (25-28). In kidneys, specific microRNAs are highly expressed and play critical roles in signaling of transforming growth factor $\beta$ during diabetic nephropathy (29-31). Moreover, depletion of microRNAs in podocytes by ablating Dicer, a key enzyme for microRNA production, results in a rapid progression 
to end-stage kidney disease, an effect that further demonstrates the involvement of microRNAs in renal development and physiology (32-34). Despite these phenomenal findings, little is known about microRNA regulation in AKI, including injury from cisplatin nephrotoxicity.

In 2007, several studies identified microRNA-34a (miR-34a) as a key target gene of p53 that is activated during DNA damage, and study results demonstrated that miR-34a might contribute to the ensuing apoptosis (35-40). Because p53 is activated during cisplatin nephrotoxicity and contributes to renal cell injury and death, we investigated miR-34a expression and its role in relevant experimental models. We showed that miR-34a is induced during cisplatin treatment of renal proximal tubular cells in vitro and mice in vivo and that miR-34a induction under these experimental conditions is p53 dependent. Interestingly, we further found evidence for a protective role of miR-34a against cisplatin-induced apoptosis in renal cells.

\section{MATERIALS AND METHODS}

\section{Cell and Special Reagents}

The mouse proximal tubular cell (BUMPT-306) line was originally obtained from W Lieberthal and JH Shwartz at Boston University (41). The cells were cultured in DMEM with $10 \%$ fetal bovine serum and $0.6 \%$ glutamine. The antibodies used were from the following sources: anti-phospho p53 (Ser-15) antibodies from Cell Signaling Technology (Danvers, MA, USA), anti-p21 antibody from Santa Cruz Biotechnology (Santa Cruz, CA, USA), and anti-puma- $\alpha$ antibody from $\mathrm{J} \mathrm{Yu}$ at the University of Pittsburgh. Cisplatin and pifithrin- $\alpha$ were purchased from Sigma (St. Louis, MO, USA). Locked-nucleic-acid (LNA) oligonucleotides were purchased from Exiqon, Vedbaek, Denmark.

\section{Cisplatin Treatment of BUMPT Cells}

Confluent BUMPT proximal tubular cells were treated with $40 \mu \mathrm{mol} / \mathrm{L}$ cis-

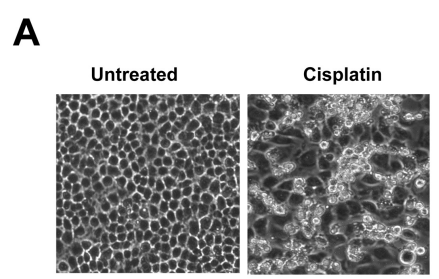

B
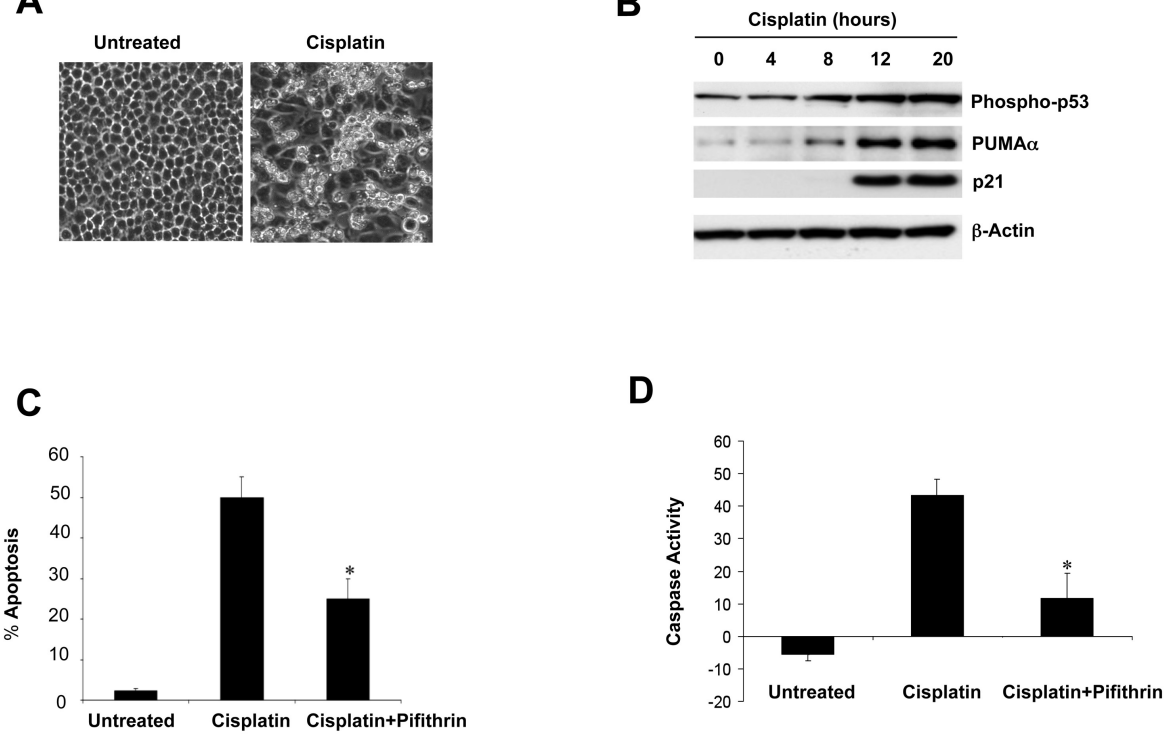

Figure 1. Cisplatin-induced apoptosis in BUMPT cells. (A) BUMPT cells were untreated or treated with $40 \mu \mathrm{mol} / \mathrm{L}$ cisplatin for $20 \mathrm{~h}$. Cell morphology was recorded by phasecontrast microscopy (10x). (B) BUMPT cells were treated with $40 \mu \mathrm{mol} / \mathrm{L}$ cisplatin for the indicated time. Whole-cell lysates were collected for immunoblot analysis of Phospho-p53 (Ser-15), Puma- $\alpha, p 21$, and $\beta$-actin (protein loading and transferring control). (C) BUMPT cells were untreated or treated with $40 \mu \mathrm{mol} / \mathrm{L}$ cisplatin for $24 \mathrm{~h}$ in the absence or presence of $20 \mu \mathrm{mol} / \mathrm{L}$ pifithrin- $\alpha$. Percentage of apoptosis was determined by counting the cells with typical apoptotic morphology. (D) BUMPT cells were treated with $40 \mu \mathrm{mol} / \mathrm{L}$ cisplatin for $20 \mathrm{~h}$ in the absence or presence of $20 \mu \mathrm{mol} / \mathrm{L}$ pifithrin- $\alpha$. Cell lysates were collected to measure caspase activity by an enzymatic assay as described in Methods. Data in C, $D$ : mean $\pm S D, n=3$; *, significantly different from the cisplatin group.

platin. After incubation for indicated time periods, the cells were morphologically examined for apoptosis or lysed to collect lysate for caspase assay or immunoblot analysis.

\section{Mouse Model of Cisplatin Nephrotoxicity}

Wild-type and p53-deficient C57BL / 6 mice (male, 8-10 wks old) were intraperitoneally injected with one dose (30 mg/ kg body weight) of cisplatin as described previously $(22,42)$. The control animals were injected with saline. To monitor renal injury, blood urea nitrogen levels were determined using the assay kit from Biotron Diagnostics (Hemet, CA, USA). Whole kidney tissues were collected for immunoblot analysis or RNA extraction. All animal experiments were performed according to a protocol approved by the institu- tional animal care and use committee of the Charlie Norwood VA Medical Center.

\section{Morphological Examination of Apoptosis and Measurement of Caspase Activity}

Cells were stained with $10 \mu \mathrm{g} / \mathrm{mL}$ Hoechst 33342 to examine cellular and nuclear morphology by phase contrast and fluorescence microscopy as described previously $(18,19)$. Typical apoptotic morphology was characterized by cellular shrinkage, formation of apoptotic bodies and nuclear condensation and fragmentation. Caspase activity was measured with an enzymatic assay by using the fluorogenic peptide DEVD.AFC, a substrate of executioner caspases including caspase-3, -6 and -7 . Briefly, cells were lysed with $1 \%$ triton $\mathrm{X}-100$ and the lysate was added to a 
caspase reaction mixture containing $50 \mu \mathrm{mol} / \mathrm{L}$ DEVD.AFC for $1 \mathrm{~h}$ of incubation. The fluorescence signal of AFC liberated by caspase activity was measured at excitation (360 nm) and emission (530 nm). Caspase activity was then calculated by using a standard curve of free AFC.

\section{Analysis of mir-34a by Real-Time Polymerase Chain Reaction}

Total RNA was extracted using the mirVana kit (Ambion, Austin, TX, USA). For real-time polymerase chain reaction (PCR), $40 \mathrm{ng}$ of total RNA was reverse-transcribed into cDNA by using the miRNA Reverse Transcription kit (Applied Biosystems, Foster City, CA, USA). Real-time PCR was carried out using the Taqman miRNA assay kit (Applied Biosystems), which included sequence-specific primers for cDNA synthesis and Taqman probes for realtime PCR. Quantification was done using $\Delta \mathrm{Ct}$ values.

\section{Northern Blot Analysis of miR-34a}

For Northern blot analysis, total RNA was extracted by using the mirVana kit (Ambion) and run on 15\% acrylamidebisacrylamide (19:1) gel containing $7 \mathrm{~mol} / \mathrm{L}$ urea in Tris-borate-EDTA buffer. The RNA was then transferred on to Hybond membrane (Amersham, Uppsala, Sweden) at $200 \mathrm{~mA}$ for $1 \mathrm{~h}$, followed by ultraviolet crosslinking. The membrane was dried at $80^{\circ} \mathrm{C}$ for $1 \mathrm{~h}$, followed by prehybridization for $1 \mathrm{~h}$ in Ultra-Hyb-Oligo hybridization buffer (Ambion). The radiolabeled probe (complementary of the mature microRNA sequence) was added to the prehybridization buffer and incubated overnight at $37^{\circ} \mathrm{C}$ and then washed in $2 \times$ standard saline citrate (Ambion) buffer $(0.1 \%$ sodium dodecyl sulfate [SDS]) and exposed to X-ray film at $-70^{\circ} \mathrm{C}$.

\section{Transfection of LNA Oligonucleotides}

BUMPT cells were plated at 50\%-60\% confluence. On the next day, the cells were transfected with $100 \mathrm{nmol} / \mathrm{L}$ of

A
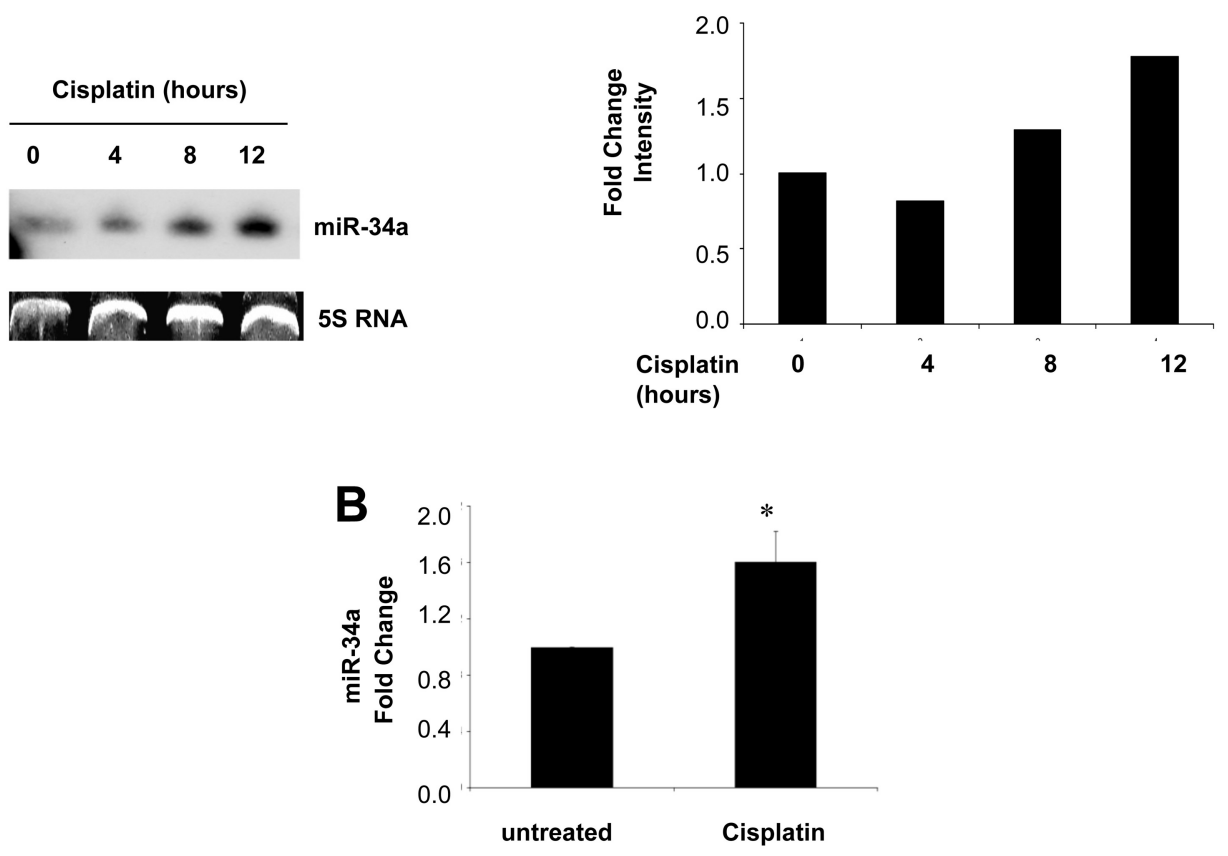

Figure 2. MicroRNA-34a induction during cisplatin treatment of BUMPT cells. (A) BUMPT cells were treated with $40 \mu \mathrm{mol} / \mathrm{L}$ cisplatin for indicated time periods. Total RNA enriched in microRNAs was then isolated for Northern blot analysis using a radiolabeled probe against mature miR-34a. 5S RNA was shown as a sample loading control. Left panel, Northern blots; right panel, densitometry analysis. For densitometry, the miR-34a signal of each condition was normalized with its 5S-RNA signal and then compared with that of the control (0 cisplatin), which was arbitrarily set as one. (B) BUMPT cells were untreated or treated with $40 \mu \mathrm{mol} / \mathrm{L}$ cisplatin for $12 \mathrm{~h}$. Total RNA enriched in microRNAs was then isolated for real-time PCR analysis by using specific primers for mature miR-34a. As an endogenous control, snoRNA-202 was also analyzed in all samples for normalization. Data: mean $\pm S D, n=3$; ${ }^{*}$, significantly different from the untreated group.

LNA oligonucleotides by use of Lipofectamine 2000 reagent. After an additional $1 \mathrm{~d}$ of culture, the cells were used for treatment.

\section{Immunoblot Analysis}

We followed a standard protocol of immunoblot analysis. Briefly, equal amounts of protein samples were loaded and resolved on SDS-polyacrylamide gel electrophoresis gels. The proteins were then transferred onto a polyvinylidenedifluoride membrane, which was blocked with $5 \%$ bovine serum albumin and incubated in primary and secondary antibodies. The antigens on the blots were revealed by use of the ECL chemiluminescence kit from Pierce (Rockford, IL, USA).

\section{RESULTS}

\section{Cisplatin-Induced Apoptosis and p53 Activation in BUMPT Cells}

In our previous studies we examined cisplatin-induced nephrotoxicity mainly using an immortalized rat kidney proximal tubular cell line and C57BL / 6 mice $(10,16,18,19,22,42)$. To facilitate microRNA research, we further characterized cisplatininduced injury in BUMPT cells, a mouse kidney proximal tubular cell line established by Lieberthal, Schwartz and colleagues at Boston University (Sinha et al. [41]). Dose-response experiments suggested that $40 \mu \mathrm{mol} / \mathrm{L}$ cisplatin for $24 \mathrm{~h}$ induced about $50 \%$ apoptosis in BUMPT cells. These cells showed a typical morphology of apoptosis, including a 
shrunken configuration and formation of apoptotic bodies (Figure 1A). The cells also had condensed and fragmented nuclei as revealed by Hoechest33342 staining (not shown). To detect p53 activation during cisplatin treatment of BUMPT cells, we collected whole-cell lysate at different time points for immunoblot analysis. As shown in Figure 1B, cisplatin induced p53 (ser-15) phosphorylation in a time-dependent manner. Consistently, cisplatin induced the expression of PUMA- $\alpha$ and p21, two transcriptional targets of p53, suggesting a robust p53 activation response during cisplatin incubation of BUMPT cells (Figure 1B). Functionally, inhibition of p53 by pifithrin- $\alpha$ partially but significantly ameliorated cisplatin-induced apoptosis in BUMPT cells. The apoptosis was suppressed by pifithrin- $\alpha$ from $50 \%$ to about $25 \%$ (Figure 1C). Pifithrin- $\alpha$ also attenuated cisplatin-induced caspase activation in BUMPT cells (Figure 1D). Together, these analyses further confirmed a role for p53 in cisplatin-induced apoptosis in BUMPT cells.

\section{Induction of miR-34a during Cisplatin Treatment of BUMPT Cells}

Little is known about microRNA regulation in AKI, including injury from cisplatin nephrotoxicity. Recent studies have demonstrated p53-dependent upregulation of microRNAs in the miR-34 family (35-39). Because p53 is activated during cisplatin treatment of renal cells and tissues, we reasoned that miR-34 might be induced under the conditions of cisplatin nephrotoxicity. To test this possibility, we initially examined miR34a expression during cisplatin treatment of BUMPT cells. BUMPT cells were incubated with $40 \mu \mathrm{mol} / \mathrm{L}$ cisplatin for 0-12 $\mathrm{h}$ to collect microRNA-enriched RNA using the mirVana kit from Ambion. The samples were initially analyzed by Northern blot analysis using a radiolabeled miR-34a-specific probe. As shown in Figure 2A, miR-34a was indeed upregulated during cisplatin treatment of BUMPT cells. The miR-34a induction was cisplatin-treatment time dependent,

A
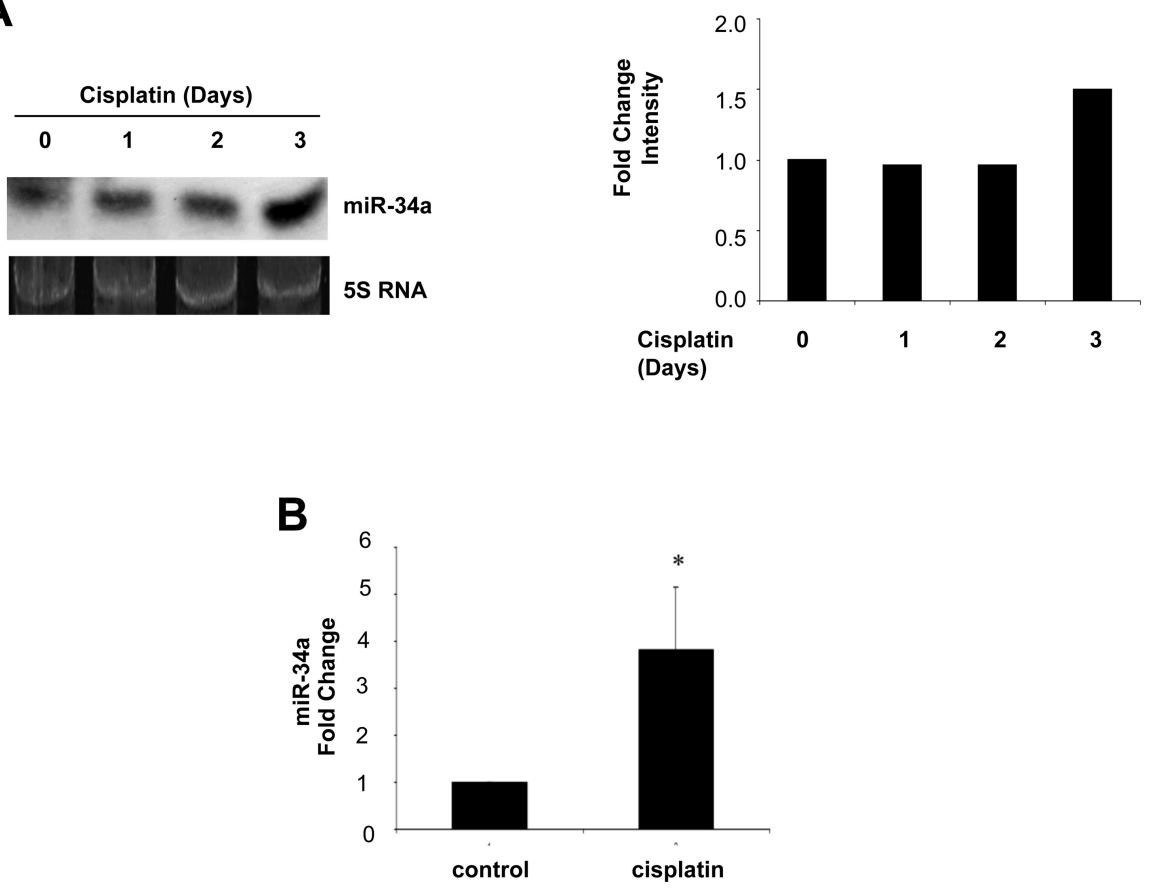

Figure 3. MicroRNA-34a induction during cisplatin treatment of C57BL/6 mice. Male C57BL/6 mice (age 8-10 wks) were injected with $30 \mathrm{mg} / \mathrm{kg}$ body weight cisplatin. Kidneys were collected at $d$ 1, 2 and 3 after cisplatin treatment for the isolation of total RNA. (A) Northen blot analysis of miR-34a expression in renal tissues. Total RNA $(10 \mu \mathrm{g})$ from renal tissues was subjected to Northern blot analysis using a specific miR-34a probe. 5S RNA was recorded as a sample loading control. Left panel, Northern blots; right panel, densitometry analysis. For densitometry, the miR-34a signal of each condition was normalized with its 5SRNA signal and then compared with that of the control (0 cisplatin), which was arbitrarily set as one. (B) Real-time PCR analysis of miR-34a. Total RNA was isolated from sham control mice and mice with $3 \mathrm{~d}$ of cisplatin treatment for real-time PCR using miR-34a-specific primers. snoRNA-202 was also analyzed in all samples as an endogenous control for normalization. Data: mean $\pm S D, n=3$; ${ }^{*}$, significantly different from the control group.

becoming noticeable at $8 \mathrm{~h}$ and increasing thereafter to a marked level at $12 \mathrm{~h}$. The results were verified by densitometry analysis of the blots (Figure 2A, right panel). To have a more quantitative measurement, we performed real-time PCR analysis. As shown in Figure 2B, the expression of miR-34a increased about 1.6fold after $12 \mathrm{~h}$ of cisplatin treatment.

\section{miR-34a Induction during Cisplatin Nephrotoxicity In Vivo}

To examine miR-34a expression during cisplatin nephrotoxicity in vivo, we used a mouse model of cisplatin nephrotoxicity. In this model, a single injection of $30 \mathrm{mg} / \mathrm{kg}$ cisplatin induced AKI in C57BL / 6 mice within 2-3 d (22,42,43). In our experiments, blood urea nitrogen was increased from the control level of $45 \mathrm{mg} / \mathrm{mL}$ to $194 \mathrm{mg} / \mathrm{dL}$ at d 3 of cisplatin treatment. We collected renal tissues on d 0,1, 2 and 3 after cisplatin injection. MicroRNA-enriched RNA samples were then isolated from the kidney tissues for Northern blot and realtime PCR analyses. Northern blot analysis showed that miR-34a was induced in renal tissues following cisplatin treatment, starting from $\mathrm{d} 1$ and becoming evident at $\mathrm{d} 3$ (Figure 3A). In real-time PCR analysis, miR-34a expression was increased to about four-fold of control at d 3 of cisplatin treatment (Figure 3B). Together, the results demonstrated miR-34a induction under in vitro and in vivo ex- 
perimental conditions of cisplatin nephrotoxicity.

\section{p53-Dependence of miR-34a Induction during Cisplatin Nephrotoxicity}

On the basis of recent findings (35-39), we hypothesized that miR-34a induction during cisplatin nephrotoxicity was mediated by $\mathrm{p} 53$. To test this possibility, we initially examined the effects of pifithrin$\alpha$ on cisplatin-induced miR-34a expression in BUMPT cells. BUMPT cells were treated for $12 \mathrm{~h}$ with cisplatin in the presence or absence of $20 \mu \mathrm{mol} / \mathrm{L}$ pifithrin- $\alpha$. Total RNA samples were collected for real-time PCR analysis. As shown in Figure $4 \mathrm{~A}$, cisplatin induced miR-34a to approximately 1.6-fold of control, which was suppressed to the control level by pifithrin- $\alpha$. We confirmed that pifithrin- $\alpha$ could suppress cisplatin-induced p53 phosphorylation or activation in BUMPT cells (Figure 4B, lane 6 versus lane 4). To further establish the role of p53 in cisplatin-induced miR-34a expression, we used p53-deficient mice. Wild-type and p53-deficient mice were injected with $30 \mathrm{mg} / \mathrm{kg}$ cisplatin and renal tissues were collected at $d 0$ and $d 3$. The tissues were then extracted for RNAs for realtime PCR analysis of miR-34a. As shown in Figure 4C, miR-34a expression in wild-type mice increased to 2.8 -fold of controls after cisplatin treatment. In sharp contrast, the expression of miR-34a in p53-deficient mice was about 0.7-fold of wild-type control tissues (Figure 4C). These results suggest that miR-34a induction during cisplatin nephrotoxicity is largely p53 dependent.

\section{Blockade of miR-34a Increases Cell Death during Cisplatin Treatment of BUMPT Cells}

The rapid induction of miR-34a shown in our experimental models of cisplatin nephrotoxicity suggested that this microRNA might participate in renal cell injury and death. To test this possibility, we used a LNA-modified antisense oligonucleotide of miR-34a (anti-miR-34a). As a control, an LNA-modified oligonucleotide

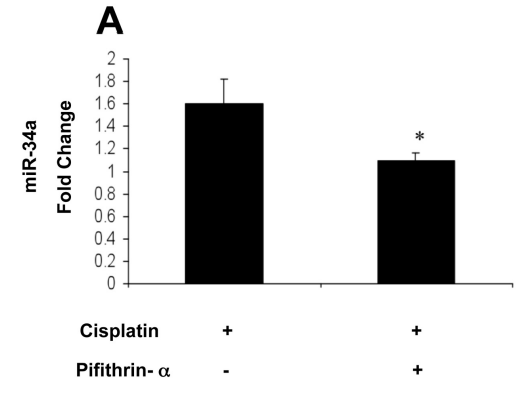

B
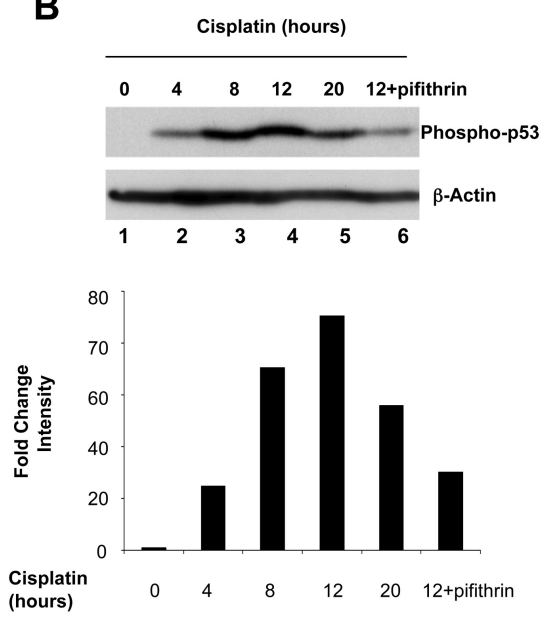

Figure 4. MicroRNA-34a induction during cisplatin nephrotoxicity is p53 dependent. (A) Effects of pifithrin- $\alpha$ on cisplatin-induced miR-34a expression in BUMPT cells. BUMPT cells were treated with $40 \mu \mathrm{mol} / \mathrm{L}$ cisplatin for $12 \mathrm{~h}$ in the presence or absence of $20 \mu \mathrm{mol} / \mathrm{L}$ pifithrin- $\alpha$. Total RNA was isolated for real-time PCR analysis of miR-34a using specific primers. (B) Effects of pifithrin- $\alpha$ on cisplatin-induced p53 activation. BUMPT cells were treated with $40 \mu \mathrm{mol} / \mathrm{L}$ cisplatin for $0-20 \mathrm{~h}$ in the presence or absence of $20 \mu \mathrm{mol} / \mathrm{L}$ pifithrin- $\alpha$. Whole cell lysates were collected for immunoblot analysis of phospho-p53 (ser-15) and $\beta$-actin. Upper panel, immunoblots; lower panel, densitometry analysis. For densitometry, the phosph-p53 signal of each condition was normalized with its $\beta$-actin signal and then compared with that of the control (0 cisplatin), which was arbitrarily set as one. (C) miR-34a induction during cisplatin treatment of wild-type and p53-deficient mice. Male wild-type and p53-deficient mice (age 8-10 wks) were injected with $30 \mathrm{mg} / \mathrm{kg}$ body weight cisplatin. Kidneys were collected at d 3 of cisplatin injection to isolate total RNA for real-time PCR analysis of miR-34a. (A,C) The miR-34a signals were normalized with that of control samples, which were arbitrarily set as one. Data are expressed as mean $\pm S D$, $\mathrm{n}=3$; * , significantly different from the cisplatin and wild-type groups.

of scrambled sequence was used (scrambled). We first verified the effects of antimiR-34a on the expression of miR-34a during cisplatin treatment. As shown in Figure 5A, cisplatin induced miR-34a in scrambled sequence-transfected cells, but not in anti-miR-34a-transfected cells. Interestingly, transfection of anti-miR-34a increased apoptosis during cisplatin treatment of BUMPT cells. Morphological evaluation revealed that cisplatin induced $43 \%$ apoptosis in scrambled sequence-transfected cells, but $53 \%$ in anti-miR-34a-transfected cells (Figure 5B). Consistently, caspase activation during cisplatin treatment was also higher in
anti-miR-34a-transfected cells (Figure 5C). We further determined the effects of anti-miR-34a on long-term survival of BUMPT cells following cisplatin treatment. To this end, the cells were incubated with cisplatin for $24 \mathrm{~h}$, followed by recovery in fresh medium for another $24 \mathrm{~h}$. Whole-cell lysate was then collected for protein determination. As shown in Figure 5D, significantly lower amounts of proteins were recovered in the anti-miR34a-transfected cells than the scrambled sequence-transfected cells (Figure 5D), suggesting that fewer cells survived cisplatin injury in the anti-miR-34atransfected group. Thus, blockade of 
A

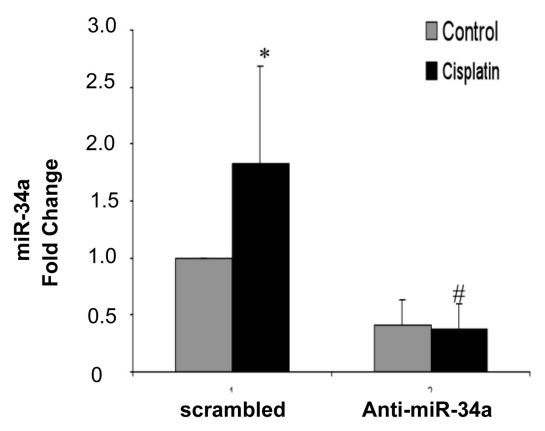

C

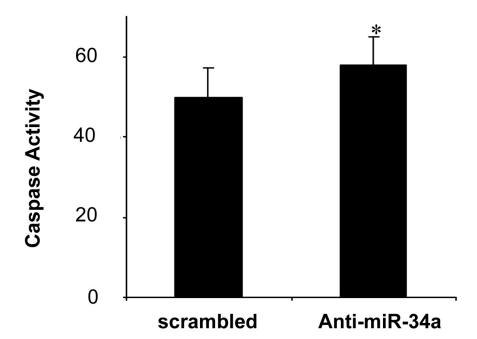

B

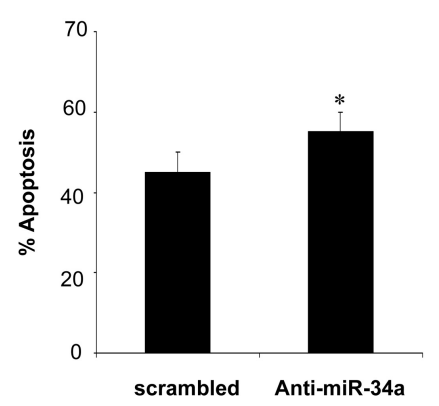

D

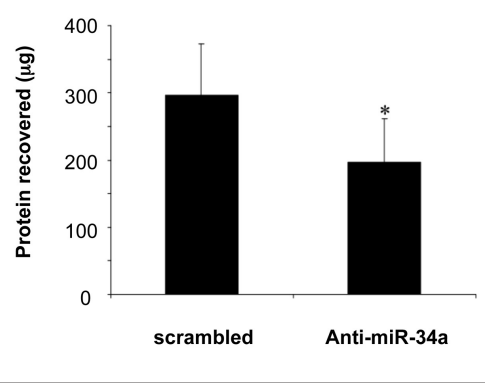

Figure 5. Blockade of miR-34a increased cisplatin-induced apoptosis in BUMPT cells. BUMPT cells were transfected with $100 \mathrm{nmol} / \mathrm{L}$ LNA-modified antisense oligonucleotide of miR-34a (anti-miR-34a) or LNA-modified oligonucleotide of scrambled sequence (scrambled). The cells were then left untreated or treated for $20 \mathrm{~h}$ with $40 \mu \mathrm{mol} / \mathrm{L}$ cisplatin. (A) Effects of anti-miR-34a on miR-34a induction during cisplatin treatment. Total RNA was isolated for real-time PCR analysis of miR-34a using specific primers. (B) Effects of anti-miR-34a on cisplatin-induced apoptosis. Percentage of apoptotic cells was determined by morphological methods. (C) Effects of anti-miR-34a on cisplatin-induced caspase activation. Cell lysate was collected for an enzymatic assay of caspase activity. (D) Effects of anti-miR-34a on cell survival following cisplatin treatment. After cisplatin treatment for $24 \mathrm{~h}$, the cells were incubated in fresh medium for $24 \mathrm{~h}$ of recovery. Whole cell lysate was then collected to determine the recovered protein to indicate cell survival. Data: mean $\pm S D, n=3$; *, significantly different from control and scrambled groups.

miR-34a increased BUMPT cell injury and death during cisplatin treatment, suggesting that miR-34a may play a cytoprotective role under these experimental conditions.

\section{DISCUSSION}

MicroRNAs have emerged as important regulators of various pathophysiological conditions (25-28). By repressing gene expression, microRNAs regulate processes of cellular activity and homeostasis, including growth, proliferation, survival and death (25-28). However, very little is known about the role and regulation of microRNAs in the develop- ment of renal diseases $(29,44)$. The results of this study, in which we used in vitro cell culture as well as in vivo mouse models, demonstrated early miR-34a induction during cisplatin-induced nephrotoxicity. The induction of miR-34a was shown to be p53 dependent. Interestingly, our results also indicate that miR34a induced during cisplatin nephrotoxicity may be a cytoprotective mechanism for cell survival.

A robust induction of miR-34a has been reported recently in response to DNA damage or genotoxic stress (35-39). Importantly, the results of these studies indicated that miR-34a is downstream of p53 and plays an important role in p53mediated apoptosis and cell-cycle arrest. In experimental models of cisplatin nephrotoxicity, our recent work has revealed a rapid DNA damage response, which is centered on ATR and Chk2 (19). The activation of ATR and Chk2 leads to the phosphorylation and activation of p53, which induces the expression of genes that promote cell death by apoptosis (19). Such genes include PUMA- $\alpha$ and PIDD $(18,20)$. Another interesting finding was that p53 might also induce the expression of genes that promote cell survival. For example, p21, a cell-cycle regulator with demonstrated antiapoptotic activity, is induced during cisplatin nephrotoxicity via both p53-dependent and -independent mechanisms (23). Our current results have demonstrated miR34a induction during cisplatin nephrotoxicity. Notably, cisplatin induced miR34a in both cultured proximal tubular (BUMPT) cells and renal tissues in C57BL / 6 mice (see Figures 2 and 3). To our knowledge, this evidence is among the first reported for microRNA regulation in an experimental model of AKI. In this study, we observed miR-34a induction during cisplatin injury, and it was not clear whether and when miR-34a expression would return to the basal level. However, it is likely that the microRNA expression profile during renal recovery or regeneration is different from that of the injury phase.

We have further provided evidence that miR-34a induction by cisplatin is mediated by p53. We showed that in BUMPT cells, miR-34a induction by cisplatin was attenuated by pifithrin- $\alpha$, a pharmacological inhibitor of p53 (Figure 4A). Furthermore, miR-34a induction during cisplatin nephrotoxicity was abrogated in p53-deficient mice (Figure 4C). In the in vivo model, $30 \mathrm{mg} / \mathrm{kg}$ cisplatin was used to induce kidney injury in C57 / BL6 mice. This dose was also used by this and other laboratories in previous studies $(22,42,43,45)$. It is noteworthy that cisplatin at $30 \mathrm{mg} / \mathrm{kg}$ induced apoptosis mainly in proximal and distal tubules in kidneys, and not in collecting 
tubules or glomeruli; some necrosis was induced and mainly localized in proximal tubules (42). Thus cisplatin at this dose does not induce widespread tissue damage, and the model is suitable for the study of cisplatin nephrotoxicity. These observations support the conclusion that $m i R-34 a$ is a transcriptional target gene of p53. In fact, the promoter region of the miR-34a gene contains p53-binding sites (38). Thus, data suggest that binding of p53 to these sites may activate the transcription of miR34a during cisplatin-induced injury in renal cells and tissues.

When miR-34a was first identified as a target gene of p53, it was shown to mediate the antiproliferative and proapoptotic effects of p53 (35-39). For example, Raver-Shapira et al. showed that antagonism of miR-34a could block etoposideinduced apoptosis in U2OS cells (37). In human colon cancer cells, Tazawa et al. showed that expression of miR-34a led to complete suppression of cell proliferation and induced senescence-like phenotypes (39). However, our current results do not support a proapoptotic role for miR-34a in cisplatin-induced injury in BUMPT cells. We showed that blockade of miR34a with LNA-modified antisense oligonucleotides increased apoptosis during cisplatin treatment of BUMPT cells (Figures 5B, C). In addition, blockade of miR-34a decreased long-term survival of the cells following cisplatin treatment (Figure 5D). Of note, in this experiment we measured the amount of total cell proteins recovered, which may not be an accurate indication of cell survival. However, the results were supported measurement results for cell death or apoptosis (Figure 5B, C). Together, the results suggest that miR-34a induction during cisplatin treatment of BUMPT cells is not proapoptotic, but instead is cytoprotective. This observation was unexpected. However, a very recent study by Kato et al. demonstrated in Caenorhabditis elegans that loss-of-function mutation of miR-34a sensitized somatic cells to radiation injury, suggesting a cytoprotective role for $\mathrm{miR}-34 \mathrm{a}$ in these cells (46). In addition, in mammalian cell lines with different levels of miR-34a, there seemed to be an inverse correlation between miR-34a expression and cellular radiosensitivity, that is, cells with low miR-34a were more sensitive to irradiation-induced injury and death (46). Together, these results and those from our current study support a cytoprotective role for miR-34a under certain experimental conditions. It is currently unclear why miR-34a has been found to be proapoptotic in some studies, but antiapoptotic in others. We speculate that miR-34a has multiple target genes, and the role played by miR-34a depends on which genes are under its regulation or suppression under various experimental conditions.

MicroRNAs regulate diverse cellular processes by repressing target gene expression. However, target identification is one of the main challenges in understanding the functional role of specific microRNAs. A microRNA can have multiple targets and the target genes of a microRNA can change under different experimental conditions. Several target genes have been suggested for miR-34a, but most of the targets are related to cell-cycle regulation. For example, cyclin E, CDK4, CDK6 and CDC25C were shown to be repressed by miR-34a, resulting in cell-cycle arrest at G1 and G2 phases (35-39). In terms of the regulation of cell death, Bommer et al. showed that $\mathrm{Bcl}-2$ is a direct target of miR-34a (40). However, regulation of $B c l-2$, a well-established antiapoptotic gene, cannot explain the cytoprotective role of miR-34a observed in our study, because repression of $\mathrm{Bcl}-2$ should sensitize the cells to cisplatin injury. In our study, expression of either miR-34a or anti-miR34a did not change the expression of Bcl-2 in BUMPT cells (data not shown), ruling out $\mathrm{Bcl}-2$ as a target gene of $\mathrm{miR}-$ $34 \mathrm{a}$ in these cells. We speculate that miR-34a induced during cisplatin nephrotoxicity may regulate or repress a proapoptotic gene(s), leading to death resistance and cell survival. Future studies should identify such gene(s) for a better understanding of the cytoprotective role of miR-34a.

In conclusion, this study has demonstrated the first evidence for microRNA regulation in an experimental model of AKI. miR-34a is induced via p53 during cisplatin nephrotoxicity and may play a cytoprotective role for cell survival.

\section{ACKNOWLEDGMENTS}

The study was supported in part by the National Institutes of Health and Department of Veterans Affairs. K Bhatt was supported by a predoctoral fellowship from the American Heart Association.

\section{DISCLOSURE}

The authors declare that they have no competing interests as defined by Molecular Medicine, or other interests that might be perceived to influence the results and discussion reported in this paper.

\section{REFERENCES}

1. Arany I, Safirstein RL. (2003) Cisplatin nephrotoxicity. Semin. Nephrol. 23:460-4.

2. Pabla N, Dong Z. (2008) Cisplatin nephrotoxicity: Mechanisms and renoprotective strategies. Kidney Int. 73:994-1007.

3. Park MS, De Leon M, Devarajan P. (2002) Cisplatin induces apoptosis in LLC-PK1 cells via activation of mitochondrial pathways. J. Am. Soc. Nephrol. 13:858-65.

4. Price PM, Safirstein RL, Megyesi J. (2004) Protection of renal cells from cisplatin toxicity by cell cycle inhibitors. Am. J. Physiol. Renal Physiol. 286: F378-84.

5. Ramesh G, Reeves WB. (2003) TNFR2-mediated apoptosis and necrosis in cisplatin-induced acute renal failure. Am. J. Physiol. Renal Physiol. 285: F610-8.

6. Ramesh G, Reeves WB. (2005) p38 MAP kinase inhibition ameliorates cisplatin nephrotoxicity in mice. Am. J. Physiol. Renal Physiol. 289: F166-74.

7. Shiraishi F, et al. (2000) Heme oxygenase-1 gene ablation or expression modulates cisplatin-induced renal tubular apoptosis. Am. J. Physiol. Renal Physiol. 278: F726-36.

8. Liu H, Baliga R. (2005) Endoplasmic reticulum stress-associated caspase 12 mediates cisplatininduced LLC-PK1 cell apoptosis. J. Am. Soc. Nephrol. 16:1985-92.

9. Nowak G. (2002) Protein kinase C-alpha and ERK1/2 mediate mitochondrial dysfunction, decreases in active $\mathrm{Na}+$ transport, and cisplatininduced apoptosis in renal cells. J Biol. Chem. 277:43377-88.

10. Jiang M, Yi X, Hsu S, Wang CY, Dong Z. (2004) Role of p53 in cisplatin-induced tubular cell apo- 
ptosis: dependence on p53 transcriptional activity. Am. J. Physiol. Renal Physiol. 287: F1140-7.

11. Li S, et al. (2004) PPAR alpha ligand protects during cisplatin-induced acute renal failure by preventing inhibition of renal FAO and PDC activity. Am. J. Physiol. Renal Physiol. 286:F572-80.

12. Lieberthal W, Triaca V, Levine J. (1996) Mechanisms of death induced by cisplatin in proximal tubular epithelial cells: apoptosis vs. necrosis. Am. J. Physiol. 270:F700-8.

13. Sheikh-Hamad D, et al. (2004) Cellular and molecular studies on cisplatin-induced apoptotic cell death in rat kidney. Arch. Toxicol. 78:147-55.

14. Liu M, et al. (2009) Transcription factor Nrf2 is protective during ischemic and nephrotoxic acute kidney injury in mice. Kidney Int. 76:277-85.

15. Cummings BS, Schnellmann RG. (2002) Cisplatininduced renal cell apoptosis: caspase 3-dependent and -independent pathways. J. Pharmacol. Exp. Ther. 302:8-17.

16. Jiang M, et al. (2007) Nutlin-3 protects kidney cells during cisplatin therapy by suppressing Bax/Bak activation. J Biol. Chem. 282:2636-45.

17. Jiang M, et al. (2007) Effects of hydroxyl radical scavenging on cisplatin-induced p53 activation, tubular cell apoptosis and nephrotoxicity. Biochem. Pharmacol. 73:1499-510.

18. Jiang M, et al. (2006) Regulation of PUMA-alpha by $\mathrm{p} 53$ in cisplatin-induced renal cell apoptosis. Oncogene. 25 4056-66.

19. Pabla N, Huang S, Mi QS, Daniel R, Dong Z. (2008) ATR-Chk2 signaling in p53 activation and DNA damage response during cisplatin-induced apoptosis. J Biol. Chem. 283:6572-83.

20. Seth R, Yang C, Kaushal V, Shah SV, Kaushal GP. (2005) p53-dependent caspase-2 activation in mitochondrial release of apoptosis-inducing factor and its role in renal tubular epithelial cell injury. J Biol. Chem. 280:31230-9.

21. Tsuruya K, et al. (2008) Involvement of p53-transactivated Puma in cisplatin-induced renal tubular cell death. Life Sciences. 83:550-6.

22. Wei $Q$, et al. (2007) Activation and involvement of p53 in cisplatin-induced nephrotoxicity. Am. J. Physiol. Renal Physiol. 293: F1282-91.

23. Megyesi J, Udvarhelyi N, Safirstein RL, Price PM. (1996) The p53-independent activation of transcription of p21 WAF1/CIP1/SDI1 after acute renal failure. Am. J. Physiol. 271: F1211-6.

24. Periyasamy-Thandavan S, et al. (2008) Autophagy is cytoprotective during cisplatin injury of renal proximal tubular cells. Kidney Int. 74:631-40.

25. Winter J, Jung S, Keller S, Gregory RI, Diederichs S. (2009) Many roads to maturity: microRNA biogenesis pathways and their regulation. Nat. Cell Biol. 11:228-34.

26. Schickel R, Boyerinas B, Park SM, Peter ME. (2008) MicroRNAs: key players in the immune system, differentiation, tumorigenesis and cell death. Oncogene 27:5959-74

27. Chang TC, Mendell JT. (2007) microRNAs in vertebrate physiology and human disease. Annu. Rev. Genomics Hum. Genet. 8:215-39.
28. Croce CM, Calin GA. (2005) miRNAs, cancer, and stem cell division. Cell 122:6-7.

29. Kato M, Arce L, Natarajan R. (2009) MicroRNAs and their role in progressive kidney diseases. Clin J. Am. Soc. Nephrol. 4:1255-66.

30. Kato M, et al. (2009) TGF-beta activates Akt kinase through a microRNA-dependent amplifying circuit targeting PTEN. Nat. Cell Biol. 11:881-9.

31. Kato M, et al. (2007) MicroRNA-192 in diabetic kidney glomeruli and its function in TGF-betainduced collagen expression via inhibition of Ebox repressors. Proc. Natl. Acad. Sci. U. S. A. 104:3432-7.

32. Harvey SJ, et al. (2008) Podocyte-specific deletion of dicer alters cytoskeletal dynamics and causes glomerular disease. J. Am. Soc. Nephrol. 19:2150-8.

33. Shi S, et al. (2008) Podocyte-selective deletion of dicer induces proteinuria and glomerulosclerosis. J. Am. Soc. Nephrol. 19:2159-69.

34. Ho J, et al. (2008) Podocyte-specific loss of functional microRNAs leads to rapid glomerular and tubular injury. J. Am. Soc. Nephrol. 19:2069-75.

35. Chang TC, et al. (2007) Transactivation of miR34 a by $\mathrm{p} 53$ broadly influences gene expression and promotes apoptosis. Mol. Cell 26:745-52.

36. He L, et al. (2007) A microRNA component of the p53 tumour suppressor network. Nature. 447:1130-4.

37. Raver-Shapira N, et al. (2007) Transcriptional activation of miR-34a contributes to p53-mediated apoptosis. Mol. Cell 26:731-43.

38. Tarasov V, et al. (2007) Differential regulation of microRNAs by p53 revealed by massively parallel sequencing: miR-34a is a p53 target that induces apoptosis and G1-arrest. Cell Cycle. 6:1586-93.

39. Tazawa $H$, Tsuchiya $N$, Izumiya $M$, Nakagama H. (2007) Tumor-suppressive miR-34a induces senescence-like growth arrest through modulation of the E2F pathway in human colon cancer cells. Proc. Natl. Acad. Sci. U. S. A. 104:15472-7.

40. Bommer GT, et al. (2007) p53-mediated activation of miRNA34 candidate tumor-suppressor genes. Curr. Biol. 17:1298-307.

41. Sinha D, Wang Z, Price VR, Schwartz JH, Lieberthal W. (2003) Chemical anoxia of tubular cells induces activation of c-Src and its translocation to the zonula adherens. Am. J. Physiol. Renal Physiol. 284: F488-97.

42. Wei Q, Dong G, Franklin J, Dong Z. (2007) The pathological role of Bax in cisplatin nephrotoxicity. Kidney Int. 72:53-62.

43. Faubel S, et al. (2007) Cisplatin-induced acute renal failure is associated with an increase in the cytokines interleukin (IL)-1beta, IL-18, IL-6, and neutrophil infiltration in the kidney. J. Pharmacol. Exp. Ther. 322:8-15.

44. Saal S, Harvey SJ. (2009) MicroRNAs and the kidney: coming of age. Curr. Opin. Nephrol. Hypertens. 18:317-23.

45. Faubel S, et al. (2004) Caspase-1-deficient mice are protected against cisplatin-induced apoptosis and acute tubular necrosis. Kidney Int. 66:2202-13.

46. Kato M, et al. (2009) The mir-34 microRNA is required for the DNA damage response in vivo in C. elegans and in vitro in human breast cancer cells. Oncogene. 28:2419-24. 